\title{
Brushless DC motor speed control strategy of simulation
}

\section{research}

Xiang $W_{E N}{ }^{1, *}$,Zhen-qiang $L I^{2}$

${ }^{1,2}$ College of Electrical and Information Engineering, Guangxi University of Science and Technology, Liuzhou Guangxi 545006, China

\begin{abstract}
In view of the brushless DC motor speed regulation problem, an ideal control strategy is designed. Through the model and analysis of Brushless DC motor, the mathematical model of the brushless DC motor is obtained. By comparing three control strategies of PID control strategy, fuzzy control strategy and fuzzy PID control strategy, PID controller, fuzzy controller and fuzzy PID controller are designed respectively for simulation test. The simulation results show that the fuzzy PID controller has good control effect.
\end{abstract}

Keywords. Brushless DC motor; Fuzzy controller; Control strategy

\section{Introduction}

The DC brushless motor is divided into two types because of the different types of its winding drive current waveforms [1]: One is the square wave permanent magnet synchronous Motor, because the armature driver current is the square wave (trapezoidal wave), which is called Brushless DC Motor. The other is the permanent magnet synchronous motor, which is called the permanent magnet synchronous motor because the armature driver current is a sine wave. Compared with the sinusoidal permanent magnet synchronous motor, brushless DC motor has obvious superiority, feedback device is simpler, the power density is higher [2], the output torque is bigger, the control structure is simpler, make the motor and inverter fully play their own potential. Therefore, the application and research of brushless DC motor have been paid more and more attention. In many cases, other kinds of motors have been replaced by their technological advantages.

Compared with other type motor, brushless DC motor in the form of square wave excitation brushless DC motor, improve the utilization rate of the permanent magnetic material and reduced the volume of motor, increasing the motor output, with high efficiency, high reliability characteristics. This paper adopts 22 conduction method [3], rotor each corner $60^{\circ}$ electrical degrees, Inverter bridge is a converter, the stator magnetic state is a corresponding change. However, the principle and process of anti-electromotive force and electromagnetic torque generation are similar to those of traditional brushless dc motors, so the analysis process is similar.

In order to ensure the stability of the motor speed, the motor speed closed loop control $[4,5,6]$ is realized by measuring the motor speed. In this paper, three control strategies, PID control strategy, fuzzy control strategy and fuzzy PID control strategy, are used to simulate the brushless DC motor.

PID control algorithm has better control effect on linear time invariant system [7]. Fuzzy control [8,9] can solve the system difficult to model the control problem, because it does not need the exact model of the controlled object, and often adjust the time is short. However, the fuzzy controller is difficult to eliminate the steady-state error because it does not have integral links. Fuzzy control PID control algorithm for nonlinear time-varying systems can achieve good control effect.

\footnotetext{
*Corresponding author: 920592971@qq.com
} 
Fuzzy PID control is a combination of fuzzy control and PID control, which takes full advantage of the advantages of both $[9,10]$. At the same time, it proves that it has better control effect.

\section{Working principle and model analysis of Brushless DC motor}

\subsection{Working principle}

In order to realize the commutation without mechanical contact, the brushless DC motor cancels the brush, and the armature winding and permanent magnet steel are placed on the stator and rotor side respectively, thus becoming the "DC -DC motor" mechanism. In order to control the speed and the rotation direction of the motor, the brushless DC motor must be realized by the rotor position sensor, the control circuit and the power inverter bridge. The power drive mode is divided into [3]: half bridge type, full bridge type (1. 22 conduction mode, 2 . 33 conduction mode), C-Dump type, $\mathrm{H}$ bridge type, Four switch type.

\subsection{Brushless DC motor, mathematical model}

The transfer function is derived from the three-phase full bridge drive and the 22 winding mode of stator winding. At this point, each phase of the stator winding leads to a 60 degree electrical angle, and each electrical cycle of the motor undergoes a 6 commutation. In the commutation process, the three-phase winding has current flow because of the diode freewheeling. When the shutdown phase current is reduced to 0 , the freewheeling diode stops, the commutation process is completed, the new motor in two-phase conduction state. Commutation torque ripple caused by commutation is an important dynamic process of Brushless DC motor.

However, due to its short duration, it has little effect on the effective value of the electrical quantity. Therefore, in the steady state analysis and the transfer function deduction, it is neglected to simplify the calculation. It is assumed that only two phase windings are connected and their currents are equal and opposite. Take A and B phase winding conduction as an example.

$$
i_{A}=-i_{B}=i
$$

The linear voltage equation of Brushless DC motor is expressed as

$$
\left[\begin{array}{l}
u_{A B} \\
u_{B C} \\
u_{C A}
\end{array}\right]=
$$

$$
\left[\begin{array}{ccc}
R & -R & 0 \\
0 & R & -R \\
-R & 0 & R
\end{array}\right]\left[\begin{array}{l}
i_{A} \\
i_{B} \\
i_{C}
\end{array}\right]+
$$

$$
\left[\begin{array}{ccc}
L-M & M-L & 0 \\
0 & L-M & M-L \\
M-L & 0 & L-M
\end{array}\right] \frac{d}{d t}\left[\begin{array}{c}
i_{A} \\
i_{B} \\
i_{C}
\end{array}\right]+\left[\begin{array}{c}
e_{A}-e_{B} \\
e_{B}-e_{C} \\
e_{C}-e_{A}
\end{array}\right]
$$

By (1.2) available

$u_{A B}=2 R i+2(L-M) \frac{d i}{d t}+\left(e_{A}-e_{B}\right)$

Irrespective of the transient process of commutation, that is, when the A and B phases are steady conduction, the size of $e_{A}$ and $e_{B}$ are equal and the sign is opposite, and the formula (1.3) can be rewritten as

$$
\begin{aligned}
u_{A B} & =U_{d}=2 R i+2(L-M) \frac{d i}{d t}+2 e_{A} \\
& =r_{a} i+L_{a} \frac{d i}{d t}+k_{e} \Omega
\end{aligned}
$$

Type: $U_{d}$-DC bus voltage;

$r_{a}$ - winding wire resistance, $r_{a}=2 \mathrm{R}$;

$L_{a}$ - winding equivalent line inductance,

$L_{a}=2(L-M)$;

$k_{e}$ - Line back EMF coefficient,

$k_{e}=2 P \Psi_{m}=4 P N S B_{m}$.

Similar to other motors, the power and torque of Brushless DC motor can be analysed from the point of view of energy transfer. The electric power from the power supply when the motor is running, the power of small part into the copper loss and iron loss, most of the air gap magnetic field to transfer torque to the rotor of the permanent magnet rotor, this power is part of the electromagnetic power, instead it is equal to the electromotive force of the three-phase winding and the phase current and the product of that.

$$
P_{e}=e_{A} i_{A}+e_{B} i_{B}+e_{B} i_{B}
$$

Regardless of mechanical losses and stray losses of the rotor, the electromagnetic power is converted into rotor kinetic energy, so

$$
P_{e}=T_{e} \Omega
$$

Type: $T_{e}$ - Electromagnetic torque;

$\Omega$ - Mechanical angular speed of motor.

By formula (1.5) and (1.6) 


$$
\begin{gathered}
T_{e}=\frac{e_{A} i_{A}+e_{A} i_{A}+e_{A} i_{A}}{\Omega} \\
e_{A}=2 \mathrm{NS} \omega B_{m} f_{A(\theta)}=\omega \Psi_{m} f_{A}(\theta)
\end{gathered}
$$

Type: $B_{m}$ - the maximum value of the air gap flux density distribution of the rotor permanent magnet;

$\Psi_{m}$ - The maximum value is_m per phase winding chain, $\Psi_{m}=2 N S B_{m}$;

$f_{A}(\theta)$ - A contrary to the waveform function of electromotive force;

$e_{A}$ - A contrary electromotive force.

By substituting (1.8) for (1.7), another form of the torque equation can be obtained

$T_{e}=\mathrm{p}\left[\Psi_{m} f_{A}(\theta) i_{A}+\Psi_{m} f_{B}(\theta) i_{B}+\Psi_{m} f_{B}(\theta) i_{B}\right]$

Type: $\mathrm{P}$ - motor pole count.

When the brushless DC motor running in $120^{\circ}$ conduction mode, without considering the phase change of transient process, so the type (1.9) can be simplified to

$$
T_{e}=2 \mathrm{p} \Psi_{m} i_{A}=K_{T} i
$$

Type: $K_{T}$ - motor torque coefficient;

$i$ - winding phase current in steady state.

Motor equation

$$
T_{e}-T_{L}=J \frac{d \Omega}{d t}+B_{v} \Omega
$$

Type: $T_{L}$ - load torque;

J - Rotor moment of inertia;

$B_{v}$ - Coefficient of viscous friction.

In formula (1.4), the relation between the bus voltage and the angular speed can be obtained by representing the current with angular velocity, and then the motor transfer function is introduced. It will be (1.10) in substitution (1.11)

$$
K_{T}-T_{L}=J \frac{d \Omega}{d t}+B_{v} \Omega
$$

The transfer function of the load will be discussed later, considering the no-load condition at which the armature current is

$$
\mathrm{i}=\frac{J}{K_{T}} \frac{d \Omega}{d t}+\frac{B_{v}}{K_{T}} \Omega
$$

Replace (1.13) with (1.4)

$$
\begin{gathered}
U_{d}=r_{a}\left(\frac{J}{K_{T}} \frac{d \Omega}{d t}+\frac{B_{v}}{K_{T}} \Omega\right)+L_{a} \frac{d}{d t}\left(\frac{J}{K_{T}} \frac{d \Omega}{d t}+\right. \\
\left.\frac{B_{v}}{K_{T}} \Omega\right)+k_{e} \Omega
\end{gathered}
$$

Therefore

$$
\begin{aligned}
U_{d}= & \frac{L_{a} J}{K_{T}} \frac{d^{2} \Omega}{d t^{2}}+\frac{r_{a} J+L_{a} B_{v}}{K_{T}} \frac{d \Omega}{d t} \\
& +\frac{r_{a} B_{v}+k_{e} K_{T}}{K_{T}} \Omega
\end{aligned}
$$

The transfer function of the brushless DC motor is obtained by Laplace transformation and sorting (1.15)

$$
\begin{aligned}
G_{u}(s) & =\frac{\Omega(s)}{U_{d}(s)} \\
& =\frac{K_{T}}{L_{a} J s^{2}+\left(r_{a} J+L_{a} B_{v}\right) s+\left(r_{a} B_{v}+k_{e} K_{T}\right)}
\end{aligned}
$$

The transfer function shown in equation (1.16) is a two order system and is sorted into the canonical form of the two order system

$$
G_{u}(s)=\frac{K_{T}}{r_{a} B_{v}+k_{e} K_{T}} \frac{\omega_{n}^{2}}{s^{2}+2 \xi \omega_{n} s+\omega_{n}^{2}}
$$

Type: $\omega_{n}=\sqrt{\frac{r_{a} B_{v}+k_{e} K_{T}}{L_{a} J}}-$ Natural frequencies of two order systems;

$$
\xi=\frac{1}{2} \frac{r_{a} J+L_{a} B_{v}}{\sqrt{L_{a} J} \sqrt{r_{a} B_{v}+k_{e} K_{T}}}-\text { Damping ratio of two }
$$

order system.

When the load is not zero, it can be regarded as the input of the system, and the system structure is shown as shown.

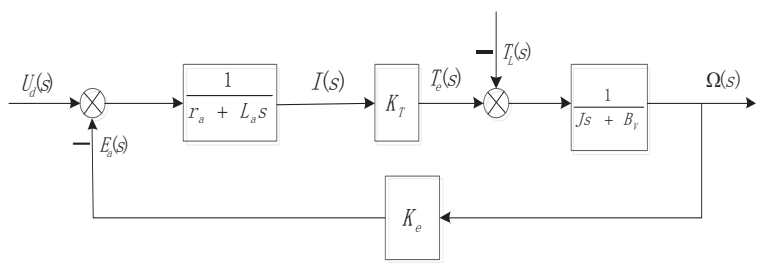

According to the superposition principle, at this time the output equals the sum of the responses of $U_{d}(s)$ and $T_{L}(s)$. When $U_{d}(s)=0$ is shown in Fig.

$\left[-k_{e} \frac{1}{r_{a}+L_{a} s} K_{T} \Omega(s)-T_{L}(s)\right] \frac{1}{J s+B_{v}}=\Omega(s)$

That is

$$
\Omega_{L}(s)\left[\frac{\left(r_{a}+L_{a} s\right)\left(J s+B_{v}\right)+k_{e} K_{T}}{\left(r_{a}+L_{a} s\right)}\right]=-T_{L}(s)
$$

At this point, the transfer function between the load torque and the speed is

$$
\begin{aligned}
G_{L}(s) & =\frac{\Omega(s)}{T_{L}(s)} \\
& =-\frac{r_{a}+L_{a} s}{L_{a} J s^{2}+\left(r_{a} J+L_{a} B_{v}\right) s+\left(r_{a} B_{v}+k_{e} K_{T}\right)}
\end{aligned}
$$

Therefore, the speed response of Brushless DC motor under the combined action of voltage and load torque is 


$$
\begin{aligned}
\Omega(s) & =G_{u}(s) U_{d}(s)+G_{L}(s) T_{L}(s) \\
& =\frac{K_{T} U_{d}(s)-\left(r_{a}+L_{a} s\right) T_{L}(s)}{L_{a} J s^{2}+\left(r_{a} J+L_{a} B_{v}\right) s+\left(r_{a} B_{v}+k_{e} K_{T}\right)}
\end{aligned}
$$

\section{Control strategy design}

The transfer function $G_{d v}$ between the known input voltage and the output speed is considered. On this basis, the block diagram of the PID controller, fuzzy controller and fuzzy PID controller are conceived respectively, as shown in figure 4.

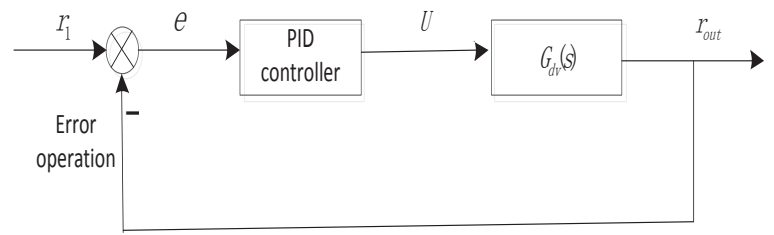

(a).PID controller

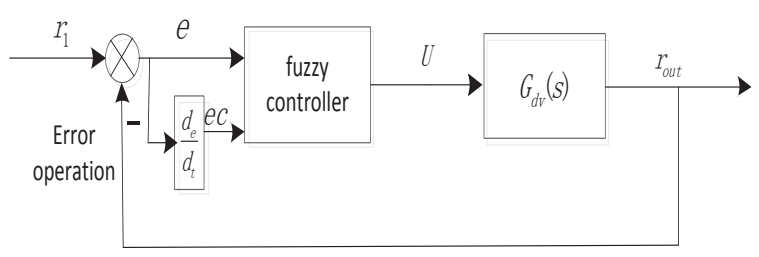

(b).fuzzy controller

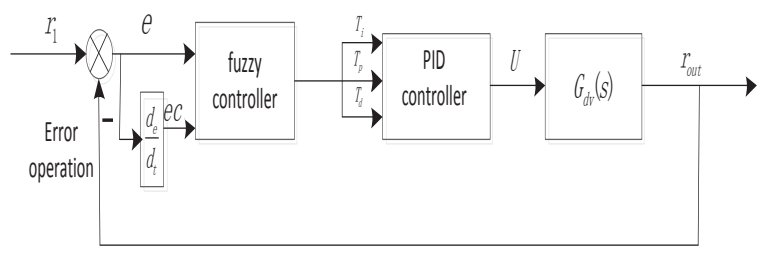

(c).fuzzy PID controller

Figure 4 three structural block diagrams

Take the main circuit parameters, respectively

$\mathrm{U}=120 \mathrm{~V}$,

$r_{a}=14 m \Omega$,

$L_{a}=0.0001 H$

$T_{\mathrm{T}}=0.0275$

$J=0.0002 \mathrm{kgm}^{2}$

$B_{V}=0.004586 \mathrm{wb}$

$K_{e}=0.0275$,

$T_{L}=10 \mathrm{Nm}$

\subsection{PID controller design}

A block diagram of the system consisting of the PID controller is shown in Figure 4 (a). The main circuit parameter is substituted into $G_{d v}$

$$
G_{d v}(s)=\frac{4.19 \times 10^{4}-1.22 S}{2.44 \times 10^{-5} s^{2}+5.58 \times 10^{-4} S+1}
$$

After the addition of PI control, the transfer function of the PI action is set to $T(s)=1+1 / s$, and the open-loop transfer function of the system becomes:

$$
G(S)=G_{d v}(S) \cdot T(S)=\frac{4.19 \times 10^{4}-1.22 S}{2.44 \times 10^{-5} S^{3}+5.58 \times 10^{-4} S^{2}+1}
$$

\section{2 fuzzy controller design}

A block diagram of the system consisting of a fuzzy controller is shown in Figure 4 (b).

The specific design process of fuzzy controller is as follows:

1) Determine the input language variables for error e and error change ec, the output variable is $\mathrm{r}$.

$$
e(k)=r_{\text {ref }}-r_{o}(k), e c(k)=e(k)-e(k-1)
$$

2) Select fuzzy subsets e,ec, $u=\{N B$ (negative large), NM (negative middle), NS (negative small), ZE (zero), PS (positive small), PM (positive middle), PB (positive large)\}.

3) Determine fuzzy control rules.

4) By resolving the ambiguity, the output control R, and then after processing, the output voltage.

\section{3 fuzzy PID controller design}

A block diagram of the system consisting of a fuzzy PID controller is shown in figure 4(c).

The fuzzy PID controller is combined with fuzzy controller and PID controller, error e and error change ec as input, using the fuzzy control rules to modify the PID parameters to meet the different moments of $\mathrm{e}$ and ec on PID parameters.

The design process is similar to the fuzzy controller. The input linguistic variables are error e and error variation ec, but the output variables become proportional, integral and differential parameters, namely, kp 、 ki and kd.

At run time, the control system completes the on-line adjustment of PID parameters by processing the fuzzy logic rules, look-up table and operation.

\section{3. simulation results and analysis}




\begin{tabular}{cccc}
\hline $\begin{array}{c}\text { simulated } \\
\text { effect }\end{array}$ & $\begin{array}{c}\text { PID } \\
\text { controller }\end{array}$ & $\begin{array}{c}\text { Fuzzy } \\
\text { controller }\end{array}$ & $\begin{array}{c}\text { Fuzzy PID } \\
\text { controller }\end{array}$ \\
\hline overshoot & big & small & small \\
debug time & long & short & middle \\
$\begin{array}{c}\text { steady-state } \\
\text { error }\end{array}$ & middle & big & small \\
\hline
\end{tabular}

To verify the effectiveness of the above three control strategies. In the MATLAB/Simulink software, the simulation models of the three schemes are built, in which the initial PID tuning parameters are consistent. The setting speed is $\Omega_{i}=1500 \mathrm{r} / \mathrm{min}$ as follows. The simulation model is shown in Figure 5 , and the simulation results are shown in Figure 6

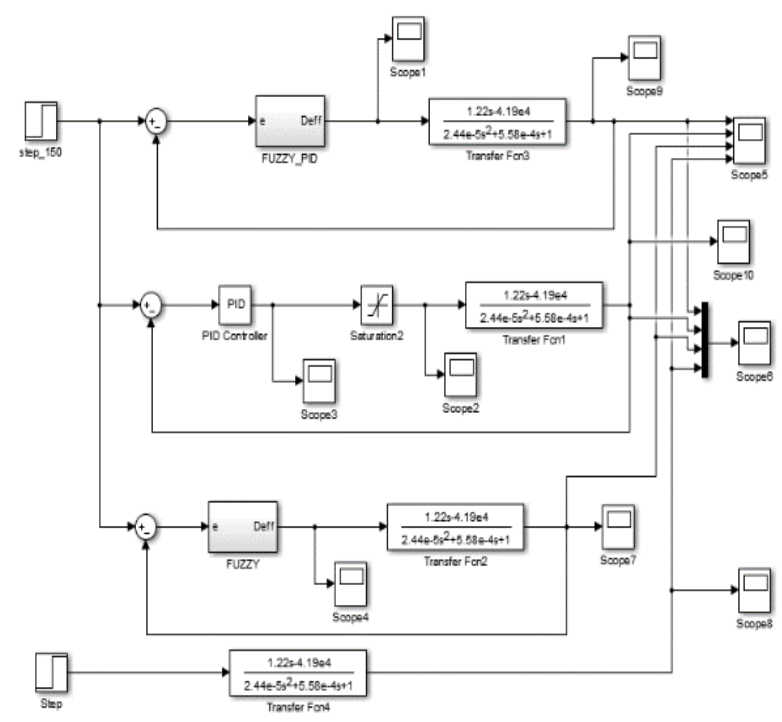

Figure 5 Simulink simulation model

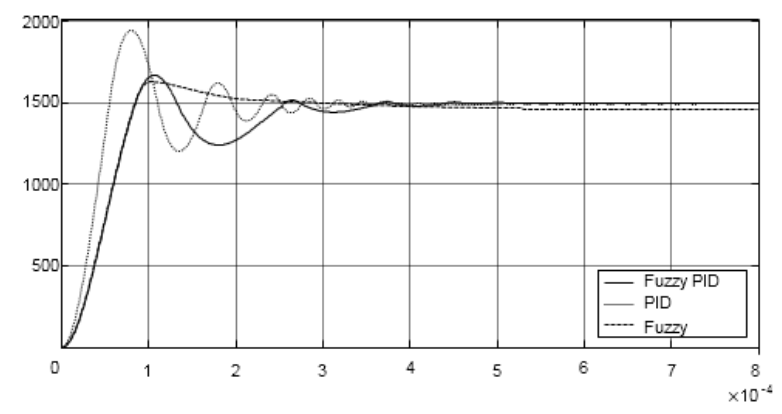

Figure. 6 Comparison of the simulation results of the three control schemes

Through the simulation, the PID overshoot is relatively large, the adjustment time is relatively long; fuzzy PID controller, the overshoot is small, the adjustment time is slightly shorter than the PID controller, the steady-state error is almost zero; fuzzy controller overshoot, and adjust the shortest time, but there is a large steady-state error. Details are shown in table 1.
Table 1 The simulation results of the three kinds of control scheme

\section{Conclusion}

In this paper, three different control strategies simulation of Brushless DC motor, through the experimental results, the fuzzy PID controller combined with fuzzy control and PID small overshoot and small steady-state error, good simulation effect.

\section{Reference}

1. Zhang Yan. DSP brushless DC motor speed control system of high performance research based on [D]. Xi'an Electronic and Science University, 2007.

2. Yin Yunhua. Design and Simulation of Brushless DC motor control system based on DSP [D]. North Central University, 2007.

3. Xia Changliang. Brushless DC motor control system [M]. Science Press, 2007..

4. Du Juan, Guo Zhonghua, Ma Hua jie. Speed control system of Brushless DC motor based on adaptive fuzzy PID control [J]. electronic technology and software engineering, 2016, (03): 139-141.

5. Lian QinJian. Design and Simulation of Brushless DC motor drive system of electric vehicle based on DSP [D]. Xi'an University Of Architecture And Technology, 2014.

6. Wang Ling, Liu Weiguo. Simulation of Brushless DC motor speed control system based on fuzzy PI control [J]. computer simulation, 2009, (10): 186-189.

7. Wei Hua, Li Qun, Chen Debao. A new nonlinear parameter fuzzy PID control method of [J]. computer technology and development, 2008,18 (2): 237-239.

8. Cheng Lirong, Sun Changzhi. Simulation of three phase brushless DC motor speed regulation system [J]. microcomputer information, 2007, (04): 251-252.

9. Zhang Jinhuan. PID control system and fuzzy adaptive PID control system research and comparison [J]. Journal of Wuhan University of Technology, 2005,27 (5): 286-290. 
10. Wang Shuyan, Shi Yu, Feng Zhongxu. Research on control method based on fuzzy PID controller [J]. mechanical science and technology, 2011,30 (1): 166-172. 